\title{
Fabrication and testing of rocket engine construction elements by addictive production approach
}

\author{
A. A. OREKHOV ${ }^{1}$, E. V. SHEMETOVA ${ }^{1}$, YAN NAING MIN ${ }^{2}$, \\ ${ }^{1}$ Moscow Aviation Institute (National Research University), Moscow, Volokolamskoe shosse, 4, 125993, RUSSIA \\ ${ }^{2}$ Defence Services Academy (D.S.A), Mandalay-Lashio highway street, Pyin Oo Lwin, Mandalay Division, MYANMAR
}

\begin{abstract}
For the first time, using the technology of selective laser sintering, prototypes of rocket engine compressor blades were manufactured with subsequent analysis of the strength, technological, physical and mechanical characteristics of the product. The physical and mechanical properties of the manufactured blades were investigated, it was found that the short-term strength limit at $20^{\circ} \mathrm{C}$ is $1450 \mathrm{MPa}$, and at $300{ }^{\circ} \mathrm{C}$ the ultimate strength is $1300 \mathrm{MPa}$, thus thermal losses in deformation resistance are no more than $12 \%$, which allows the material to be used in aircraft construction, including for supersonic aircraft.
\end{abstract}

Keywords-Addictive production, strength, composites, 3D printing.

Received: February 10, 2021. Revised: August 11, 2021. Accepted: August 26, 2021. Published: September 1, 2021.

\section{Introduction}

$\mathrm{A}$ CCORDING to the structure of the additive manufacturing market, the main directions are automotive, medicine, industry, consumer electronics, architecture, as well as aviation and aerospace due to significant investments of major aviation companies in the development of industrial applications of additive manufacturing [1]-[18]. The development of modern aircraft is proceeding at a rapid pace, which places increased demands on traditional production technologies, which are becoming increasingly difficult to compete with modern ones, for example, 3D printing. This technology allows not only to build a model quickly and at low cost, but also to demonstrate the assembly and operation process. For the aviation industry, one of the main drivers of improvement is the reduction in the weight of the flying components [19]-[35]. The additive manufacturing process is capable of creating physical parts starting from a digital input. Furthermore, a wide range of composite materials based on nanocomponents described in [36]-[60] can be successfully used for addictive manufacturing process. In order to achieve the required geometry, various operating parameters, such as tool paths and projections, must be defined in the software, which depend on the material and equipment used. This is one of the biggest advantages of additive manufacturing: production of parts with little need for special tooling to determine the shape [61]-[79].

Low-thrust rocket engines such as electric rocket motors are widely used in space technology to stabilize and correct the orbits of geostationary satellites, and as propulsion engines for spacecraft in several interplanetary missions. The principle of operation of an electric rocket engine consists in organizing a plasma discharge of the working gas with subsequent acceleration of plasma ions using an electric field. The outflow rate of working gas ions is significantly higher than in traditional chemical rocket engines. For various types of electric rocket engines, it ranges from 5 to $60 \mathrm{~km} / \mathrm{s}$, which allows significant savings in the mass of the working fluid with a significant resource of their work, amounting to several tens of thousands of hours. A decrease in the mass of the working body makes it possible to increase the mass of the spacecraft payload. In one of the schemes of this engine - a highfrequency ion engine - the working gas plasma is formed under the influence of a high-frequency electromagnetic field inside a thin-walled bowl of a ceramic gas-discharge chamber. To increase the power of such an engine, it is necessary to increase the diameter of the gas-discharge chamber to a value of $500 \mathrm{~mm}$ and more while maintaining the wall thickness at the same level (no thicker than 4-5 mm). The used samples of gas-discharge chambers made of alumina ceramics and a ceramic composite based on silicon nitride with a chamber diameter of up to $160 \mathrm{~mm}$, in principle, have sufficient operational properties. However, an increase in the diameter of the gas-discharge chambers above $160 \mathrm{~mm}$ is significantly limited by the capabilities of the technology for the production of ceramic products. In addition, along with the difficulty of forming and sintering such items, a significant operational problem of ceramic gas-discharge chambers is their low resistance to vibration loads arising during the launch of spacecraft into near-earth orbit. The solution to this problem would be to manufacture gas-discharge chambers from a composite material of the composition: ceramic particles (fibers) - organosilicon or ceramic matrix. The advantages of such composite materials are, above all, their high dielectric properties and very high vibration resistance. The matrix of such materials can be made from silicone elastomers. Finely dispersed powders of such inorganic ceramic materials as aluminum, beryllium or silicon oxides, boron or silicon nitrides, etc. can be used as a dispersed filler.

Prospects for the creation of the proposed new class of composite materials open up significant opportunities in the development of new structural materials for space technology: the creation of multifunctional composites with increased 
parameters of rigidity, thermal stability and damping will allow in the future to implement products with increased mass efficiency. Thus, the volume of structural materials of engines, the density of which is very high (to ensure the required strength and heat resistance), as part of the structure of spacecraft can be reduced.

The fundamental nature of the problem under consideration lies in the fact that technologies for creating such composite materials and ceramic fillers do not currently exist. For example, for the particle size of ceramic fillers (from tens of nanometers to tens of microns), the optimal calculated thickness of the polymer matrix should be from a few to hundreds of nanometers, which requires the implementation of new coating techniques, the development of new methods for dispersing the filler and curing the samples. These methods should ensure the possibility of obtaining high-quality defectfree samples of gas-discharge chambers of a given (calculated) thickness. In particular, one of the most difficult problems in the formation of ceramic products is the need to work with the original ceramic masses containing coarse (up to 100 microns and higher) grains with abrasive properties. Initial compositions for prototyping, having such particles in their granulometric composition, significantly complicate the $3 \mathrm{D}$ printing process due to the constant clogging of technological channels as a result of their sedimentation. Fighting channel clogging is usually accomplished by widening the flow area, which ultimately reduces print accuracy. The development of promising techniques for manufacturing products using 3D printing from a wide range of materials is, therefore, an extremely urgent task.

The next task is to develop approaches to the creation of dispersed systems synthesized in a discharge of nano- and microparticles of organic-inorganic materials in the form of particles with organosilicon polymer coatings, to study the principles of their formation and properties, including using ultrasonic cavitation, as well as the principles of 3D - printing of composite materials from ceramic nanoparticles and polymer/ceramic matrices. An important point in the technology being developed is the optimization of the process of passage of dispersions of large (up to 200 microns) ceramic particles in paraffinic technological bonds with a low content of paraffin at temperatures close to the solidification temperature of the bond through the technological channels (for example, the print head nozzle) of the installation. For this, along with precise control of the temperature of the modeling composition, it is proposed to use the effect of ultrasonic cavitation directly in narrow channels by introducing an indenter into the channel.

Since the resulting composite material has an anisotropic nature of heat transfer (thermal conductivity is described not by a scalar quantity - a coefficient, but by a tensor), for accurate modeling of temperature fields, it is necessary to accurately determine the thermophysical characteristics, including the nonlinear dependences of the components of the thermal conductivity tensor on temperature, since otherwise, computational experiments in modeling temperature fields can give significant errors.

At the final stage, experimental studies of the dynamic properties of samples of the investigated materials (components and composites) will be carried out to confirm the results of calculations and their correction (if necessary), theoretical studies and modeling of the effect of uneven coating thickness, polydisperse fractional composition and imperfection of the shape of ceramic filler particles on effective dynamic properties of the composite, determination of the optimal compositions of composites taking into account these effects. Modeling the effective damping properties of the considered composites under shock loading and optimizing the structure to obtain impact-resistant materials with effective parameters of absorption of mechanical energy, as well as modeling the thermoelastic and strength characteristics of dispersed-reinforced composites, samples of gas-discharge chambers and comparing the calculations with the experimental results.

The technological task of the work is the development and manufacture of the installation and debugging of a new technology of three-dimensional modeling and the release of experimental samples of gas-discharge chambers in order to identify the fundamental possibilities of this molding method for obtaining ceramic parts of low-thrust rocket engines. The operations of forming and sintering powders are one of the most critical operations in the technological cycle for producing ceramic products. It is at these stages of the production cycle of obtaining a ceramic product that its main mechanical properties are formed.

The task of technological preparation of additive manufacturing on an experimental installation for layer-bylayer modeling of composite ceramic samples includes the calculation of layer-by-layer representation in accordance with the geometric shape of the part, as well as from the formation of trajectories of motion of the actuators of the experimental installation to fill the internal volumes of the part workpiece being grown. The structure of the software designed to run on a personal computer should provide technological preparation for the manufacture of the product and the formation of a set of control commands in the lowest-level and universal (as far as possible) form, but without reference to the hardware features of a particular actuator.

Thus, the aim of the work was to manufacture a rocket engine compressor blade using selective laser sintering technology, to analyze the strength and technological characteristics, and to control the quality of the resulting workpiece.

\section{Procedure of selective laser sintering}

Before carrying out the selective laser sintering process, the electronic model of the blades was saved in the STL (Stereolithography) format, intended for storing threedimensional models in additive technologies. The Selective Laser Melting (SLM) installation has been prepared in 
accordance with the instruction manual. The selective laser sintering process has already been studied by several groups of researchers [1]-[8]. The sintering process took place automatically. The metal-powder composition was placed into the feed hopper of the SLM installation, the building plate was bolted, after which the selective laser sintering process was launched in automatic mode on the control panel of the SLM installation. The blades were obtained, shown in Fig. 1. In order to facilitate the subsequent examination, before removing the blades from the installation, the primary cleaning of the blanks in the build chamber from the metal-powder composition was carried out using a molar brush, for which the glove port on the door of the building chamber of the SLM installation was opened in accordance with the instruction manual.

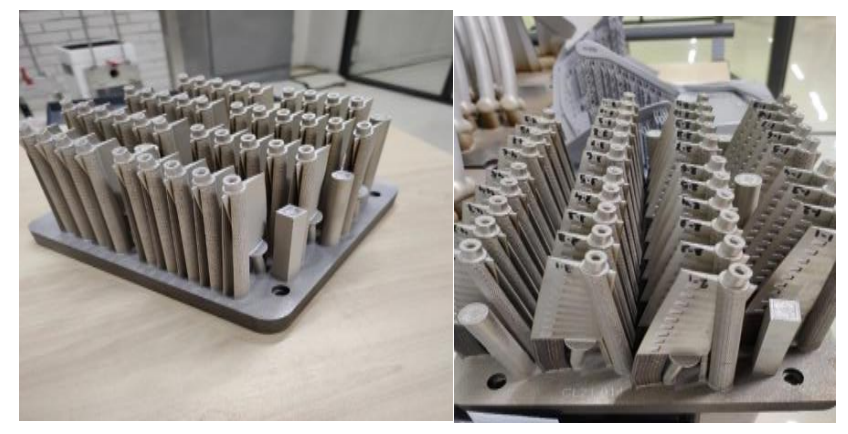

Fig. 1 rd blades obtained by selective laser sintering.

The microstructure of the blades was studied using an Axiovert 40 MAT microscope at $\mathrm{x} 50$ magnification. The wall thickness and porosity were measured at the leading edge of the blade, which is shown in Fig. 2.

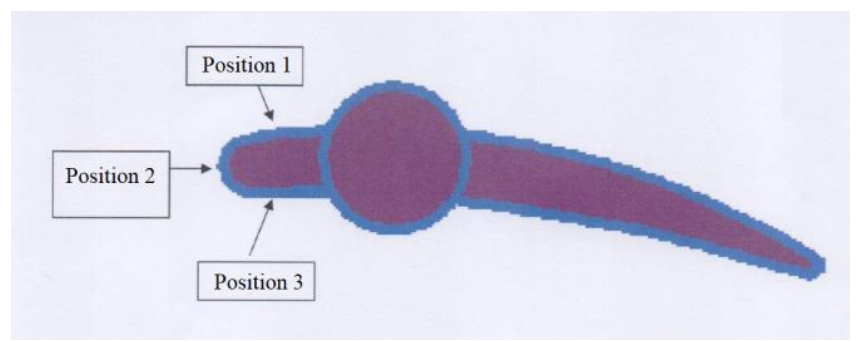

Fig. 2 cross section of the blade.

According to the measurement results, the thickness of position 1 is $0,68 \ldots 0,75 \mathrm{~mm}$, the value of position 2 is $0,34 \ldots$ $0,37 \mathrm{~mm}$, the wall thickness from the side of position 3 is 0,47 ... $0,53 \mathrm{~mm}$. The structure of the blades is a melt bath in the form of segments of a circle. There is no overheating (melting) and burnout in the microstructure of the material of the blades, there are no cold and hot cracks.

\section{Microscopy and X-ray control}

A metallographic study of the blades was carried out. Luminescence analysis showed the presence of a powder nonfusion defect with a size of $0,085 \times 0,043 \mathrm{~mm}$. Scanning electron microscopy (SEM) studies showed the microstructure of blades with no defects (Fig. 3).

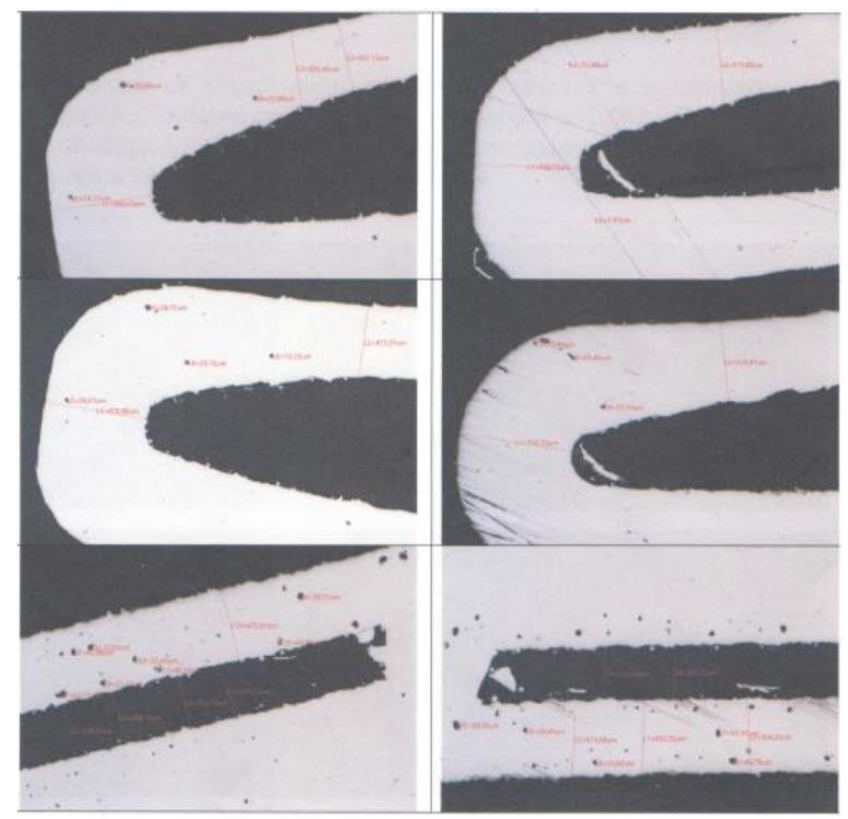

Fig. 3 results of SEM control of a rocket engine blade.

It should be noted that the surface of the blades is subjected to subsequent machining, and any metallurgical defects that can be removed by the machining are allowed.

The mechanical characteristics of the blades were determined and uniaxial tensile tests were carried out on the sample. The results obtained showed that the blades made by the selective laser sintering method have the same characteristics and quality as the blades made by the traditional method.

\section{Conclusion}

A pilot batch of rocket engine compressor blades was manufactured using the selective laser sintering technology (SLS). The study of the obtained blanks was carried out by the method of X-ray and luminescent non-destructive testing to ensure the quality of resulting materials. It is shown that there are no defects in the structure of the blades, and the identified defects in the surface layer of the material can be easily removed by subsequent mechanical treatment. The proposed technology opens the prospective for facilitated fabrication of high-quality blades for heavy duty rocket engines.

This study was funded by RFBR, project number 19-3190142 . 


\section{References}

[1] V. N. Dobryanskiy, L. N. Rabinskiy, O. V. Tushavina, "Validation of methodology for modeling effects of loss of stability in thin-walled parts manufactured using SLM technology," Periodico Tche Quimica, 16(33), pp. 650656, 2019.

[2] V. F. Formalev, S. A. Kolesnik, E. L. Kuznetsova, "Analytical study on heat transfer in anisotropic space with thermal conductivity tensor components depending on temperature," Periodico Tche Quimica, 15(Special Issue 1), pp. 426-432, 2018.

[3] V. F. Formalev, S. A. Kolesnik, "Temperature-dependent anisotropic bodies thermal conductivity tensor components identification method," International Journal of Heat and Mass Transfer, 123, pp. 994-998, 2018.

[4] V. F. Formalev, E. M. Kartashov, S. A. Kolesnik, "Simulation of Nonequilibrium Heat Transfer in an Anisotropic Semispace Under the Action of a Point Heat Source," Journal of Engineering Physics and Thermophysics, 92(6), pp. 1537-1547, 2019.

[5] I. S. Kurchatov, N. A. Bulychev, S. A. Kolesnik, "Obtaining Spectral Characteristics of Semiconductors of AIIBVI Type Alloyed with Iron Ions Using Direct Matrix Analysis," International Journal of Recent Technology and Engineering, vol. 8, i. 3, pp. 8328-8330, 2018.

[6] V. F. Formalev, S. A. Kolesnik, E. L. Kuznetsova, "Identification of new law for decomposition of bonding heat-shielding composite materials," Asia Life Sciences, (1), pp. 139-148, 2019.

[7] E. L. Kuznetsova, A. V. Makarenko, "Mathematical model of energy efficiency of mechatronic modules and power sources for prospective mobile objects," Periodico Tche Quimica, 16 (32), pp. 529-541, 2019.

[8] L. N. Rabinskiy, E. L. Kuznetsova, "Analytical and numerical study of heat and mass transfer in composite materials on the basis of the solution of a stefan-type problem," Periodico Tche Quimica, 15 (Special Issue 1), pp. 339-347, 2018.

[9] V. F. Formalev, S. A. Kolesnik, E. L. Kuznetsova, "Analytical solution-based study of the nonstationary thermal state of anisotropic composite materials," Composites: Mechanics, Computations, Applications, 9(3), pp. 223-237, 2018.

[10] V. F. Formalev, S. A. Kolesnik, "On Thermal Solitons during Wave Heat Transfer in Restricted Areas," High Temperature, 57(4), pp. 498-502, 2019.

[11]N. A. Bulychev, E. L. Kuznetsova, "Ultrasonic Application of Nanostructured Coatings on Metals," Russian Engineering Research, 39 (9), pp. 809-812, 2019.

[12]N. A. Bulychev, V. V. Bodryshev, L. N. Rabinskiy, "Analysis of geometric characteristics of two-phase polymer-solvent systems during the separation of solutions according to the intensity of the image of micrographs," Periodico Tche Quimica, 16(32), pp. 551559, 2019.

[13]L. N. Rabinskii, O. V. Tushavina, "Composite Heat Shields in Intense Energy Fluxes with Diffusion," Russian Engineering Research, 39(9), pp. 800-803, 2019.
[14]L. N. Rabinskiy, O. V. Tushavina, "Investigation of the influence of thermal and climate effects on the performance of tiled thermal protection of spacecraft," Periodico Tche Quimica, 16(33), pp. 657-667, 2019.

[15] V. V. Bodryshev, L. N. Rabinskiy, L. G. Nartova, N. P. Korzhov, "Geometry analysis of supersonic flow around two axially symmetrical bodies using the digital image processing method," Periódico Tchê Química, vol. 16, no. 33, pp. 541-548, 2019.

[16] V. F. Formalev, S. A. Kolesnik, E. L. Kuznetsova, L. N. Rabinskiy, "Origination and propagation of temperature solitons with wave heat transfer in the bounded area during additive technological processes," Periodico Tche Quimica, 16(33), pp. 505-515, 2019.

[17] V. F. Formalev, S. A. Kolesnik, E. L. Kuznetsova, "Mathematical modeling of a new method of thermal protection based on the injection of special coolants," Periodico Tche Quimica, 16(32), pp. 598-607, 2019.

[18]N. A. Bulychev, M. A. Kazaryan, A. I. Erokhin, A. S. Averyushkin, L. N. Rabinskii, V. V. Bodryshev, B. A. Garibyan, "Analysis of the Structure of the Adsorbed Polymer Layers on the Surfaces of Russian Metallurgy (Metally)," vol. 2019, no. 13, pp. 1319-1325.

[19] V. F. Formalev, S. A. Kolesnik, B. A. Garibyan, "Mathematical modeling of heat transfer in anisotropic plate with internal sinks," AIP Conference Proceedings, 2181, 020003, 2019.

[20] V. F. Formalev, S. A. Kolesnik, B. A. Garibyan, Heat transfer with absorption in anisotropic thermal protection of high-temperature products, "Herald of the Bauman Moscow State Technical University, Series Natural Sciences," (5), pp. 35-49, 2019.

[21] S. A. Kolesnik, N. A. Bulychev, "Numerical analytic method for solving the inverse coefficient problem of heat conduction in anisotropic half-space," Journal of Physics: Conference Series, 1474(1), 012024, 2020.

[22] V. F. Formalev, N. A. Bulychev, S. A. Kolesnik, M. A. Kazaryan, "Thermal state of the package of cooled gasdynamic microlasers," Proceedings of SPIE - The International Society for Optical Engineering, 11322, article number 113221B, 2019.

[23] V. F. Formalev, S. A. Kolesnik, B. A. Garibyan, "Analytical solution of the problem of conjugate heat transfer between a gasdynamic boundary layer and anisotropic strip," Herald of the Bauman Moscow State Technical University, Series Natural Sciences, 5(92), pp. 44-59, 2020.

[24] Y. Sun, S. A. Kolesnik, E. L. Kuznetsova, "Mathematical modeling of coupled heat transfer on cooled gas turbine blades," INCAS Bulletin, 12(Special Issue), pp. 193-200, 2020.

[25]I. Kurchatov, N. Bulychev, S. Kolesnik, E. Muravev, "Application of the direct matrix analysis method for calculating the parameters of the luminescence spectra of the iron ion in zinc sulfide crystals," AIP Conference Proceedings, 2181, 020015, 2019.

[26] V. F. Formalev, S. A. Kolesnik, "On Inverse Coefficient Heat-Conduction Problems on Reconstruction of 
Nonlinear Components of the Thermal-Conductivity Tensor of Anisotropic Bodies," Journal of Engineering Physics and Thermophysics, 90(6), pp. 1302-1309, 2017.

[27] V. F. Formalev, S. A. Kolesnik, "Analytical investigation of heat transfer in an anisotropic band with heat fluxes assigned at the boundaries," Journal of Engineering Physics and Thermophysics, 89(4), pp. 975-984, 2016.

[28] B. A. Antufev, E. L. Kuznetsova, L. N. Rabinskiy, O. V. Tushavina, "Investigation of a complex stress-strain state of a cylindrical shell with a dynamically collapsing internal elastic base under the influence of temperature fields of various physical nature," Asia Life Sciences, (2), pp. 689-696, 2019.

[29] B. A. Antufev, E. L. Kuznetsova, L. N. Rabinskiy, O. V. Tushavina, "Complex stressed deformed state of a cylindrical shell with a dynamically destructive internal elastic base under the action of temperature fields of various physical nature," Asia Life Sciences, (2), pp. 775782, 2019.

[30] L. N. Rabinskiy, O. V. Tushavina, "Problems of land reclamation and heat protection of biological objects against contamination by the aviation and rocket launch site," Journal of Environmental Management and Tourism, 10(5), pp. 967-973, 2019.

[31]A. N. Astapov, I. P. Lifanov, L. N. Rabinskiy, "Perspective Heat-Resistant Coating for Protection of $\mathrm{Cf} / \mathrm{SiC}$ Composites in Air Plasma Hypersonic Flow," High Temperature, 57(5), pp. 744-752, 2019.

[32] M. Sha, Y. A. Utkin, O. V. Tushavina, P. F. Pronina, "Experimental studies of heat and mass transfer from tip models made of carbon-carbon composite material $(\mathrm{cccm})$ under conditions of high-intensity thermal load," Periodico Tche Quimica, vol.17, i. 35, pp. 988-997, 2020.

[33] O. A. Pashkov, "Influence of Polymer Coatings on the Mechanical Properties of Steel Samples in Tensile and Bending Tests," Turkish Journal of Computer and Mathematics Education (TURCOMAT), vol. 12, no. 5, pp. 542-548, 2021.

[34] O. A. Pashkov, "Investigation of the Effect of Steel Plate Size and Elevated Temperature on Critical Load in Stability Tests," Turkish Journal of Computer and Mathematics Education (TURCOMAT), vol. 12, no. 10, pp. 1657-1663, 2021.

[35] Y. Sun, O. V. Egorova, E. L. Kuznetsova, "Identification of the front angle of a plane acoustic oblique pressure wave on convex surfaces with the use of analytical solution," Journal of the Balkan Tribological Association, 27(2), pp. 189-197, 2021.

[36] O. A. Butusova, "Surface Modification of Titanium Dioxide Microparticles Under Ultrasonic Treatment," International Journal of Pharmaceutical Research, vol. 12, i. 4, pp. 2292-2296, 2020.

[37] O. A. Butusova, "Stabilization of Carbon Microparticles by High-Molecular Surfactants," International Journal of Pharmaceutical Research, vol. 12, Supplementary Issue 2, pp. 1147-1151, 2020.

[38] Yu. V. Ioni, A. Ethiraj, "New Tailor-Made Polymer Stabilizers for Aqueous Dispersions of Hydrophobic
Carbon Nanoparticles," International Journal of Pharmaceutical Research, vol. 12, i. 4, pp. 3443-3446, 2020.

[39] Yu. V. Ioni, "Nanoparticles of noble metals on the surface of graphene flakes," Periodico Tche Quimica, vol. 17, no. 36, pp. 1199-1211, 2020.

[40] O. A. Butusova, "Vinyl Ether Copolymers as Stabilizers of Carbon Black Suspensions," International Journal of Pharmaceutical Research, vol. 12, Supplementary Issue 2, pp. 1152-1155, 2020.

[41] M. O. Kaptakov, "Catalytic Desulfuration of Oil Products under Ultrasonic Treatment," International Journal of Pharmaceutical Research, vol. 12, Supplementary Issue 2, pp. 1838-1843, 2020.

[42] B. A. Garibyan, "Enhancement of Mechanical Properties of Inorganic Glass under Ultrasonic Treatment," International Journal of Pharmaceutical Research, vol. 12, Supplementary Issue 2, pp. 1829-1832, 2020.

[43] M. O. Kaptakov, "Enhancement of Quality of Oil Products under Ultrasonic Treatment," International Journal of Pharmaceutical Research, vol. 12, Supplementary Issue 2, pp. 1851-1855, 2020.

[44] O. A. Butusova, "Adsorption Behaviour of Ethylhydroxyethyl Cellulose on the Surface of Microparticles of Titanium and Ferrous Oxides," International Journal of Pharmaceutical Research, vol. 12, Supplementary Issue 2, pp. 1156-1159, 2020.

[45]A. N. Tarasova, "Vibration-based Method for Mechanochemical Coating Metallic Surfaces," International Journal of Pharmaceutical Research, vol. 12, Supplementary Issue 2, pp. 1160-1168, 2020.

[46]B. A. Garibyan, "Mechanical Properties of Electroconductive Ceramics," International Journal of Pharmaceutical Research, vol. 12, Supplementary Issue 2, pp. 1825-1828, 2020.

[47]M. O. Kaptakov, "Effect of Ultrasonic Treatment on Stability of $\mathrm{TiO}_{2}$ Aqueous Dispersions in Presence of Water-Soluble Polymers," International Journal of Pharmaceutical Research, vol. 12, Supplementary Issue 2, pp. 1821-1824, 2020.

[48] Yu. V. Ioni, "Synthesis of Metal Oxide Nanoparticles and Formation of Nanostructured Layers on Surfaces under Ultrasonic Vibrations," International Journal of Pharmaceutical Research, vol. 12, i. 4, pp. 3432-3435, 2020.

[49]A. N. Tarasova, "Effect of Reagent Concentrations on Equilibria in Water-Soluble Complexes," International Journal of Pharmaceutical Research, vol. 12, Supplementary Issue 2, pp. 1169-1172, 2020.

[50]A. N. Tarasova, "Effect of Vibration on Physical Properties of Polymeric Latexes," International Journal of Pharmaceutical Research, vol. 12, Supplementary Issue 2, pp. 1173-1180, 2020.

[51] Yu. V. Ioni, A. Ethiraj, "Study of Microparticles Surface Modification by Electrokinetic Potential Measuring," International Journal of Pharmaceutical Research, vol. 12, i. 4, pp. 3436-3439, 2020. 
[52] Yu. V. Ioni, "Effect of Ultrasonic Treatment on Properties of Aqueous Dispersions of Inorganic and Organic Particles in Presence of Water-Soluble Polymers," International Journal of Pharmaceutical Research, vol. 12, i. 4, pp. 3440-3442, 2020.

[53] O. A. Butusova, "Design and Properties of Magnetically Controlled Sorbents," Turkish Journal of Computer and Mathematics Education (TURCOMAT), vol. 12, no. 5, pp. 515-519, 2021.

[54] O. A. Butusova, "Application of Magnetically Controlled Sorbents for Detoxication," Turkish Journal of Computer and Mathematics Education (TURCOMAT), vol. 12, no. 5, pp. 520-524, 2021.

[55]M. O. Kaptakov, "Effect of Thin Polymer Layers on Mechanical Properties of Metal Surfaces," Turkish Journal of Computer and Mathematics Education (TURCOMAT), vol. 12, no. 5, pp. 525-529, 2021.

[56]B. A. Garibyan, "Determination of the Elastic Modulus of the Coating Using a Spherical Indenter," Turkish Journal of Computer and Mathematics Education (TURCOMAT), vol. 12, no. 10, pp. 1594-1600, 2021.

[57] M. O. Kaptakov, "Modelling of Mechanical Properties of Metal Plates with Polymer Coatings," Turkish Journal of Computer and Mathematics Education (TURCOMAT), vol. 12 , no. 5, pp. 530-534, 2021.

[58]B. A. Garibyan, "Theoretical Estimations of Influence of Polymer Coatings on the Elastic Modulus and Ultimate Strength of Steel Samples," Turkish Journal of Computer and Mathematics Education (TURCOMAT), vol. 12, no. 10, pp. 1651-1656, 2021.

[59]M. O. Kaptakov, "Investigation of Effective Mechanical Characteristics of Nanomodified Carbon-Epoxide Composite by Numerical and Analytical Methods," Turkish Journal of Computer and Mathematics Education (TURCOMAT), vol. 12, no. 5, pp. 535-541, 2021.

[60]M. O. Kaptakov, "Obtaining of Carbon Fibers Based Composite Materials and Study of Their Mechanical Properties," Turkish Journal of Computer and Mathematics Education (TURCOMAT), vol. 12, no. 10, pp. 1601-1605, 2021.

[61] P. F. Pronina, O. V. Tushavina, E. I. Starovoitov, "Study of the radiation situation in moscow by investigating elastoplastic bodies in a neutron flux taking into account thermal effects," Periodico Tche Quimica, 17(35), pp. 753-764, 2020.

[62] A. V. Babaytsev, L. N. Rabinskiy, K. T. Aung, "Investigation of the contact zone of a cylindrical shell located between two parallel rigid plates with a gap," INCAS Bulletin, 12(Special Issue), pp. 43-52, 2020.

[63] O. A. Pashkov, "Theoretical calculation of the thickness of interphase zones in the Al-Al2O3 composite," Turkish Journal of Computer and Mathematics Education (TURCOMAT), vol. 12, no. 10, pp. 1672-1677, 2021.

[64] O. A. Pashkov, "Experimental and Theoretical Study of Mechanical Properties of Matrix Composite Materials," Turkish Journal of Computer and Mathematics Education (TURCOMAT), vol. 12, no. 10, pp. 1678-1684, 2021.
[65] V. G. Dmitriev, O. V. Egorova, E. I. Starovoitov, "Particularities of mathematical modeling of deformation processes for arched and panel designs of composites with large displacements and rotation angles," NCAS Bulletin, 12(Special Issue), pp. 53-66, 2020.

[66]O. V. Egorova, E. I. Starovoitov, "Non-stationary diffraction problem of a plane oblique pressure wave on the shell in the form of a hyperbolic cylinder taking into account the dissipation effect," INCAS Bulletin, 12(Special Issue), pp. 67-77, 2020.

[67] O. V. Tushavina, "Coupled heat transfer between a viscous shock gasdynamic layer and a transversely streamlined anisotropic half-space," INCAS Bulletin, 12 (Special Issue), pp. 211-220, 2020.

[68] S. Vakhneev, E. Starovoitov, "Damping of circular composite viscoelastic plate vibration under neutron irradiation," Journal of Applied Engineering Science, 18(4), pp. 699-704, 2020.

[69] V. A. Pogodin, L. N. Rabinskii, S. A. Sitnikov, "3D Printing of Components for the Gas-Discharge Chamber of Electric Rocket Engines," Russian Engineering Research, vol. 39, no. 9. pp. 797-799, 2019.

[70] Y. K. Kyaw, E. L. Kuznetsova, A. V. Makarenko "Complex mathematical modelling of mechatronic modules of promising mobile objects," INCAS Bulletin, 12(Special Issue), pp. 91-98, 2020.

[71]L. E. Kuznetsova, V. G. Fedotenkov, "Dynamics of a spherical enclosure in a liquid during ultrasonic cavitation," Journal of Applied Engineering Science, 18(4), pp. $681-686,2020$.

[72]N. A. Kucheva, V. Kohlert, "Mathematical modeling methods for estimation the thermophysical properties of heat-protective composite materials," Turkish Journal of Computer and Mathematics Education (TURCOMAT), vol. 12, no. 10, pp. 1606-1612, 2021.

[73]N. A. Kucheva, "Investigation of the mechanical properties of heat-protective highly porous composite materials using the effective medium model," Turkish Journal of Computer and Mathematics Education (TURCOMAT), vol. 12, no. 10, pp. 1613-1621, 2021.

[74]N. A. Kucheva, V. Kohlert, "Analytical solution of the problem of thermoelasticity for a plate heated by a source with a constant heat supply on one surface," Turkish Journal of Computer and Mathematics Education (TURCOMAT), vol. 12, no. 10, pp. 1622-1633, 2021.

[75] A. V. Makarenko, E. L. Kuznetsova, "Energy-Efficient Actuator for the Control System of Promising Vehicles," Russian Engineering Research, 39(9), pp. 776-779, 2019.

[76]E. L. Kuznetsova, A. V. Makarenko, "Mathematic simulation of energy-efficient power supply sources for mechatronic modules of promising mobile objects," Periodico Tche Quimica, 15 (Special Issue 1), pp. 330338, 2018.

[77] Y. Li, A. M. Arutiunian, E. L. Kuznetsova, G. V. Fedotenkov, "Method for solving plane unsteady contact problems for rigid stamp and elastic half-space with a cavity of arbitrary geometry and location," INCAS Bulletin, 12(Special Issue), pp. 99-113, 2020. 
[78] E. L. Kuznetsova, G. V. Fedotenkov, E. I. Starovoitov, "Methods of diagnostic of pipe mechanical damage using functional analysis, neural networks and method of finite elements," INCAS Bulletin, 12(Special Issue), pp. 79-90, 2020.

[79] Y. K. Kyaw, P. F. Pronina, P. O. Polyakov, "Mathematical modelling of the effect of heat fluxes from external sources on the surface of spacecraft," Journal of Applied Engineering Science, 18(4), pp. 732-736, 2020.

\section{Creative Commons Attribution License 4.0 (Attribution 4.0 International, CC BY 4.0)}

This article is published under the terms of the Creative Commons Attribution License 4.0

https://creativecommons.org/licenses/by/4.0/deed.en_US 